\title{
Critical Hot Plasticity and Transverse Cracking in Continuous Slab Casting with Particular Reference to Composition*
}

\author{
By N.E. HANNERZ**
}

\begin{abstract}
Synopsis
The influence of alloy and residual elements on transverse rebend cracking at continuous slab casting was studied. Statistical evaluation of one year's production comprising 35530 slabs is set in relation to the hot plasticity of the steels. Thermomechanical simulation of the cooling and the rebend strain cycle on a Gleeble machine was used to evaluate plasticity in the critical temperature range. Generally elements that increase transverse cracking negatively influence hot plasticity, which demonstrates that the simulation technique can be used to predict transverse cracking susceptibility.

Elements as $\mathrm{Nb}, \mathrm{Al}, \mathrm{Al}+\mathrm{N}, \mathrm{V}$ appear to be detrimental, while $\mathrm{N}$ according to the Gleeble studies had no detrimental effect except when in combination with $\mathrm{Al}$. Due possibly to a scavenging effect $\mathrm{Ti}$ improves plasticity of $\mathrm{Al}+\mathrm{N}$ containing steels. High contents of $\mathrm{P}$ improve plasticity and production statistics gave similar indications. Further a raised content of $\mathrm{C}$ within the range might improve resistance to transverse cracking. Statistics as well as hot plasticity testing point towards a beneficial influence of $\mathrm{B}$. Also the influence of $\mathrm{Cu}$ and $\mathrm{Mo}$ was studied. The significant detrimental influence of $\mathbf{S}$ obtained from production statistics was not reflected by a similar drop of plasticity at Gleeble simulation. The results are discussed in terms of recent publications with due consideration to the influence of physical metallurgical factors.
\end{abstract}

\section{Background}

Since the continuous casting method was taken into use time spent on surface scarfing and grinding of slabs was larger than with ingot casting.

There were doubts as to the origin of the transverse surface cracks, the temperature range in which they formed, and the mechanism behind. The location to the bottom of oscillation marks indicated that cracks formed at some very high temperature near to solidification. Observations that cracks were more frequent on the upper side of the strand however led to the conclusion that cracks formed during the rebending of the curved strand. In later years expressions like rebend cracks, unbend cracks or straightening cracks, are heard although opinions are still expressed that surface strains large enough to result in cracks may in critical cases also be caused by the centering of the strand combined with thermal stresses. Thus in the mid seventies it was commonly agreed that transverse cracking was mainly due to lack of plasticity at bending. An early Swedish interest in handling these problems on a scientific basis is illustrated by the paper of Josefsson and Schmidt. ${ }^{1)}$

It was decided in Sweden in 1976 that surface quality problems should be studied systematically by simulating rebending with the Gleeble (a thermomechanical simulator) which results then could be compared with production statistics. This project immediately gave valuable information. Now time has come to present the results to a wider public, taking into consideration also studies in other countries.

\section{Hot Plasticity}

Hot plasticity of mild and low alloy steels is very good when compared to special steels. At hot rolling the plasticity of mild steel seems to be next to infinite. However, at press forgoing alloy as well as residual elements may cause surface hot breakage, thus it is possible to find references to the hot plasticity problem from times long before steel makers started to use continuous casting as a production method. What is the similarity between press forging and rebending of the continuously cast strand? Both processes are made in the same temperature range 1200 to $700{ }^{\circ} \mathrm{C}$ and at slow deformation rates $10^{-4}$ to $10^{-6} \mathrm{sec}^{-1}$ as compared to that of hot rolling $10 \sim$ $1000 \mathrm{sec}^{-1}$. At the temperatures and deformation rates in question the hot plasticity $v s$. temperature forms a trough the bottom of which is to be found at about $750{ }^{\circ} \mathrm{C}$. Plasticity starts to drop off at about $900{ }^{\circ} \mathrm{C}$ and is regained to some extent at lower temperatures about $600{ }^{\circ} \mathrm{C}$ when austenite is all transformed. Figures 4 to 12 show typical mild steel plasticity vs. temperature trough curves. Cracks will nucleate and grow in the grain boundaries by mechanisms similar to those of diffusion creep rupture.

The influence of a third element in solid solution or as precipitated particle on hot plasticity should thus be viewed in terms of salient models for creep rupture, i.e. nucleation of grain boundary voids and growth of voids by diffusion of vacancies or grain boundary sliding and on the other hand of dynamic recrystallisation which may have a healing effect by moving boundaries away from voids and giving rise to a refined structure.

Precipitates may block sliding, block grain growth, nucleate voids, hinder dynamic recrystallisation. Elements in solid solution may strengthen grain interior to result in larger strains in the grain boundary region, it may slow down climb and vacancy diffusion and it may hinder nucleation of voids by filling out grain boundary kink positions etc. To complicate further in the present case there is an influence of temperature on transition from austenite to ferrite. This last factor may not be the least important one, as there seems to be some coincidence between the

* Manuscript received on March 9, 1984; accepted in the final form on August 27, 1984. (C) 1985 ISIJ

** Formerly Oxelösund Works, Svenskt Stál AB, Sweden. Now at Laboratory of Thermal Processing of Materials, Technical University of Denmark, Denmark. 
temperature of least plasticity and that of transformation.

Thus the field is open for physical metallurgical explanations, to which the last years' literature bears witness. This will be returned to in the final discussion on the influence of each element.

\section{Statistical Evaluation of One Year's Pro- duction in Oxelösund}

Statistical evaluation of production frequency of defects had been carried through earlier, more or less regularly. It readily came out that some steel types were more prone to cracking than others. For ordinary mild steel there were few registered slabs with these surface defects while for high tensile steels they were an order of magnitude more dominant. This information, however, could not be rationalised in terms of chemical analysis. However, by combining information out of two different data records this was made possible-one record containing information on the surface quality of the slabs and the other on the chemical analysis, mechanical properties etc. The study started after a period of staggered incidents of slab and plate surface problems when the proportion of low carbon, sulphur refined steels were higher than usual. To cover up this period it was decided to evaluate the production from one year back, with one year's duration to even out seasonic influences. The statistical study came to cover 35530 slabs produced in Oxelösund form end October, 1976, 11 months ahead. A first attempt to use the material unscreened to correlate slab surface quality to chemistry showed that due to covariations in chemistry this approach would not yeild reliable information. Therefore the production was divided into groups of steel types like mild steel, HT steel, QT steel, LPG steel, etc. Within each group of steels it was possible to make a linear regression and correlation approach to the problem. Comparing the results for a specific element in the different groups gave a back check on the reliability of the information obtained. The records contained two different criteria for transversal cracks that could be used namely per cent scarfing losses (scarfing to $75 \%$ due to transversal surface cracks) and slabs classified to contain defect code 4, transversal cracks. These two criteria have been used as dependent variables in a linear regression evaluation with the elements of the chemical analysis as independent variables.

Steel groups studied, number of slabs, relative scarfing losses and per cent slabs with defect code 4 are shown in Table 1. Slabs with defect code 4 are those which were directed to the scarfing station due to transversal cracks. Up to $100 \%$ of the surface may have cracks down to just a few transversal cracks some centimeters of length, i.e., what can be observed visually by the operator. The two surface cracking critieria follow each other as shown in Table 1 which reflects the large difference between standard and higher qualities of steel in respect of transverse cracking. Microalloy steels especially such with low carbon content are difficult to cast free from surface cracks, while mild steel is extremely castable.

For each steel group the linear regression approach including correlation analyses was tried. As a detailed report of this analysis, that showed a rather varying degree of significance, would lead us too far, only some features of interest will be discussed here.

\section{Steel Group A-Low Temperature Steel}

Within this group smallest and largest element content was G: $0.07 / 0.14 \%$, Si: $0.16 / 0.35 \%, \mathrm{Mn}$ :

Table 1. Relative influence of elements on surface transverse cracking. Statistical evaluation

\begin{tabular}{|c|c|c|c|c|c|c|c|c|c|c|}
\hline Steel group & $\begin{array}{l}\text { Total No. } \\
\text { of slabs }\end{array}$ & Cracking criterion & $\%$ & $\mathrm{G}$ & $\mathrm{Si}$ & $\mathrm{Mn}$ & $\mathrm{Cr}$ & $\mathrm{Ni}$ & Mo & $\mathrm{Cu}$ \\
\hline $\begin{array}{l}\text { A : Low temp. steel notch } \\
\text { toughness at }-60\end{array}$ & 3806 & $\begin{array}{l}\text { Scarfing losses } \\
\text { Defect code } 4\end{array}$ & $\begin{array}{l}0.60 \\
21\end{array}$ & & & & + & & & - \\
\hline $\begin{array}{l}\text { B : Low temp. steel, special } \\
\text { grade }\end{array}$ & 338 & $\begin{array}{l}\text { Scarfing losses } \\
\text { Defect code } 4\end{array}$ & $\begin{array}{l}0.52 \\
23\end{array}$ & - & & $(-)$ & & - & & \\
\hline G: QT steels & 407 & $\begin{array}{l}\text { Scarfing losses } \\
\text { Defect code } 4\end{array}$ & $\begin{array}{l}0.93 \\
26\end{array}$ & $\begin{array}{l}-- \\
--\end{array}$ & + & $(-)$ & & & & \\
\hline D : Mild steels & 12600 & $\begin{array}{l}\text { Scarfing losses } \\
\text { Defect code } 4\end{array}$ & $\begin{array}{l}0.16 \\
3\end{array}$ & $(-)$ & $(-)$ & & & & $(+)$ & \\
\hline $\begin{array}{l}\mathrm{E}: \text { Mild steels thicker } \\
\text { plates with some } \mathrm{Nb}\end{array}$ & 2562 & $\begin{array}{l}\text { Scarfing losses } \\
\text { Defect code } 4\end{array}$ & $\begin{array}{l}0.15 \\
1\end{array}$ & & & & + & & & $(-)$ \\
\hline $\mathrm{F}: \mathrm{NbAl}$ fine grain & 8670 & $\begin{array}{l}\text { Scarfing losses } \\
\text { Defect code } 4\end{array}$ & $\begin{array}{l}0.20 \\
5\end{array}$ & - & & & & ++ & & \\
\hline $\begin{aligned} \mathrm{G}: & \text { NbAl fine grain steel, } \\
& \text { normal }+Z \text { grades }\end{aligned}$ & 8531 & $\begin{array}{l}\text { Scarfing losses } \\
\text { Defect code } 4\end{array}$ & $\begin{array}{l}0.20 \\
4 *\end{array}$ & -- & & & & + & & \\
\hline \multicolumn{3}{|c|}{$\begin{array}{l}\text { This is to be read: } 4 \% \text { of the slabs were } \\
\text { classified to have defect code } 4 \text {. }\end{array}$} & $\begin{array}{c}(+) \\
+ \\
++\end{array}$ & $\begin{array}{l}\text { ncreasi } \\
\text { ncreasi } \\
\text { ncreasi }\end{array}$ & $\begin{array}{l}\text { tend } \\
\text { tend } \\
\text { tend }\end{array}$ & $\begin{array}{l}y \text { to } \\
\text { y to } \\
\text { y to }\end{array}$ & $\begin{array}{l}\text { ckir } \\
\text { ckin }\end{array}$ & hardly & gnific & \\
\hline
\end{tabular}


$1.34 / 1.65 \%, \mathrm{~N}: 0.004 / 0.015 \%$, Ce: $0 / 0.04 \%, \mathrm{Al}$ : $0.016 / 0.055 \%, \mathrm{Nb}: 0 / 0.032 \%$. All heats were low in sulphur as a result of TN or ASEA-SKF ladle treatment. With TN CaSi was used for purification while in the ASEA process Ce was used both to purge the steel and as sulphide shape controller. A correlation matrix showed that niobium, nitrogen and aluminium have a significant influence on relative scarfing losses, and frequency of defect code. 4 . If the 8th step in the stepwise regression is used the resultant equations run as follows

Relative scarfing losses:

$$
\begin{aligned}
= & -2.07+4.26 \mathrm{Si}+61.2 \mathrm{~S}+3.2 \mathrm{Cr}-229 \mathrm{Cu} \\
& +14 \mathrm{Al}+13.3 \mathrm{Nb}+24.9 \mathrm{~V}+56.2 \mathrm{~N}(\%)
\end{aligned}
$$

Frequency of slabs with defect code 4

transversal cracks:

$$
\begin{aligned}
= & -1.78+2.72 \mathrm{Si}+38.2 \mathrm{Gu}+18 \mathrm{Al} \\
& +13.5 \mathrm{Nb}+7.3 \mathrm{~V}-16.6 \mathrm{Ti}+43.2 \mathrm{~N}
\end{aligned}
$$

The results concerning copper and titanium cannot be taken seriously as these elements are only residuals $\max$ content being $0.007 \%$. For the other elements, however, the very strong relative influence of nitrogen and sulphur should be pointed out.

\section{Steel Group B-Special Grade of Low Temperature Steel}

Also for this very small group there is a very strong statistical indication that increased nitrogen leads to larger scarfing losses.

\section{Steel Group $C-Q T$ Steels}

\begin{tabular}{|c|c|c|c|c|c|c|c|c|}
\hline $\mathrm{P}$ & $\mathrm{S}$ & $\mathrm{Al}$ & $\mathrm{Nb}$ & $\mathrm{V}$ & $\mathrm{Ti}$ & $\mathrm{N}$ & $\mathrm{Ce}$ & B \\
\hline & + & $\begin{array}{l}+ \\
+\end{array}$ & $\begin{array}{c}+ \\
++\end{array}$ & + & & $\begin{array}{c}+ \\
+\end{array}$ & $(-)$ & \\
\hline $\begin{array}{c}(-) \\
-\end{array}$ & & - & & & & ++ & - & \\
\hline$(-)$ & ++ & & & & & & & $\begin{array}{l}- \\
(-)\end{array}$ \\
\hline $\begin{array}{c}(-) \\
-\end{array}$ & $\begin{array}{l}++ \\
++\end{array}$ & & & & & & & \\
\hline- & & & & & + & $\begin{array}{l}++ \\
++\end{array}$ & & \\
\hline- & ++ & $\begin{array}{c}+ \\
++\end{array}$ & $\begin{array}{c}+ \\
++\end{array}$ & + & & $\begin{array}{l}++ \\
++\end{array}$ & & \\
\hline$(-)$ & $\begin{array}{l}++ \\
++\end{array}$ & $\begin{array}{l}+ \\
+\end{array}$ & & & & $\begin{array}{l}++ \\
++\end{array}$ & & \\
\hline
\end{tabular}

All slabs in this group contained $\mathrm{Ti}-\mathrm{Al}-\mathrm{B}-\mathrm{V}$ and often also $\mathrm{Nb}$ intentionally added. The small popu-

of one year's production.

(-) Decreasing tendency to cracking (hardly significant)

- Decreasing tendency to cracking

- Decreasing tendency to cracking (strongly significant) lation, 407 slabs, indicates that most QT steels in these days were ingot cast, one reason being surface cracking another being centre line lamellation problems. In this case as for the other groups a strong influence of nitrogen content on the surface cracking tendency can be noted. Also sulphur significantly increases surface transverse cracking. Increasing content of cerium, copper and boron seems to lower cracking tendency, this is particularly true for boron. Independent of criterion, scarfing losses or defect code 4, the defects decreased with increasing boron content from 0.001 to $0.003 \%$ B. A very strong beneficial influence of carbon is noted.

\section{Steel Group D-Mild Steel}

This is the largest group, with the least proportion of cracking. Relative scarfing losses increase with sulphur content as do frequency of slabs with defect code 4. A mild beneficial influence of phosphorous is noted.

\section{Steel Group E-Mild Steel for Thicker Plates (Con- tains Some Nb)}

Also for this group there is a strong tendency that surface transverse cracking increases with nitrogen content.

\section{Steel Group F-High Strength Al Nb Fine Grain Steels}

Sulphur and nitrogen have the strongest significant influence on both crack criteria. After these elements come aluminium and niobium. If we look at the seventh step in the linear regression we can form a picture of how strong an influence the elements have relatively on surface defects and thereby scarfing.

Slabs with defect code 4 :

$$
\begin{aligned}
& =-0.37+0.29 \mathrm{Si}-2.3 \mathrm{P}+5.3 \mathrm{~S}+4.9 \mathrm{Ni} \\
& +1.35 \mathrm{Al}+3.57 \mathrm{Nb}+6.26 \mathrm{~N}
\end{aligned}
$$

The influence of phosphorous is rather unexpected but actually there is a rather general trend that phosphorous lowers the tendency to cracking.

\section{Steel Group G-High Strength Micro-alloyed Steel- Normal and $Z$ Grade}

This group consists of high strength steels fine grain treated with both aluminium and niobium both in bulk quality and in $Z$ plate version, i.e., sulphur refined. The sulphur refined steels are produced either over TN or the ASEA-SKF process.

Also for this group nitrogen is the element that strongest influences surface cracking, next in significance comes sulphur. Relatively seen, however, nitrogen is very much stronger in this respect than sulphur as shown by the below equations.

Relative scarfing losses:

$$
=-0.34+12.0 \mathrm{~S}+69 \mathrm{~N}(\%)
$$

Frequency of slabs with defect code 4 :

$$
-0.15+3.7 \mathrm{~S}+27 \mathrm{~N}
$$


For other steel groups the influence of these two elements, however, is of about equal numerical size.

\section{General Conclusions}

As seen from the above for each group some information has emerged and in Table 1 it is tried to gather this information for each element in question. Table 1 can be read as follows. There are strong indications that nitrogen is detrimental, and there also are indications of a detrimental influence of sulphur. Indications that aluminium and niobium are deleterious are not quite so strong. However, here we must bear in mind that all heats were aluminiumtreated and within each group the niobium content (with group A as an exception) was also rather constant. For carbon and phosphorous it seems that increased content of these elements will lower the susceptibility to transversal cracking. Only group $\mathrm{C}$ steels were boron treated and it appears from that rather small group that raised boron will also decrease the tendency to transverse cracking. For the other alloy and residual elements it is not possible to make reliable deductions partly depending on the statistical material during the studied period. Very few titanium or vanadium heats were cast, no heats with raised copper content etc.

The lack in overall trends for manganese, silicon, cromium, molybdenum and nickel may indicate that the influence of these elements is marginal. The outcome of the study, however, is interesting enough, and it can be recommended that steel producers with different mixes of analyses make similar evaluations.

\section{Simulation of the Rebend Operation}

The simplest way to simulate the straightening of the strand would be to heat the specimen to say $1300{ }^{\circ} \mathrm{C}$, cool the specimen continually with the same nominal speed as the strand surface is cooled and deform it slowly at specified temperatures defined as tentative rebend temperatures and then measure the plasticity of the specimen. There may be two objections to such a simulation. Firstly in the real case the strand surface is cooled from solidification temperature and not from $1300{ }^{\circ} \mathrm{C}$. Secondly in the real case the surface is cooled by water jets, then it is reheated from the interior so that the temperature actually oscillates with an amplitude of 50 to $100{ }^{\circ} \mathrm{C}$.

Bernard $^{2)}$ has discussed the first objection. $\mathrm{He}$ came to the conclusion that the grain size and position of the grain boundaries at time of rebend in reference to primary solidification microsegregation were actually independent of whether the steel solidified as $\delta$ or as $\gamma$. Suzuki et $a l .{ }^{3}$ ) found that the plasticity trough was wider if the peak temperature was $1400^{\circ} \mathrm{C}$ than if it was $1300^{\circ} \mathrm{C}$. They also showed that in-situ melting and resolidifying the Gleeble specimen prior to cooling did not give a wider trough than the 1400 peak temperature cycle. Peak temperature $1300^{\circ} \mathrm{G}$ has been chosen by French researchers ${ }^{2,4)}$ for simulation on rebend cracking. Two British investigations used $1300{ }^{\circ} \mathrm{C}^{5,6)}$ and another $1330^{\circ} \mathrm{C}^{7,8)}$ while a third used $1250{ }^{\circ} \mathrm{C} .{ }^{9,10}$ In different Japa-

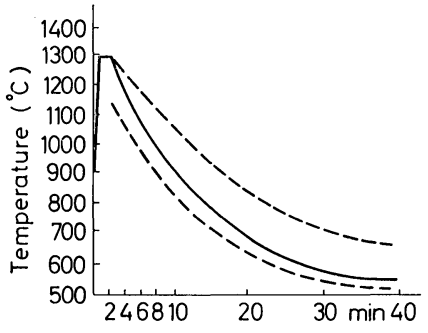

Dotted lines: the upper and lower oscillation temperature in an actual case of strand cooling.

Fig. 1. The Gleeble specimens were cooled down to the deformation temperature according to the solid line.

nese studies peak temperatures from 1450 to $1200{ }^{\circ} \mathrm{C}$ have been used ${ }^{11-13)}$ Schmidt and Josefsson ${ }^{1)}$ stressed that cooling the steel down rapidly to the $\alpha$-region whereupon it could heat up again to the $\gamma$-region would lessen the strand surface grain sizes and thus decrease the surface cracking. Since then many workers have studied different oscillating cooling patterns $s^{11,13,14)}$ or the influence of a hold period at lower temperatures. ${ }^{2,6)}$ It is evident that oscillation influences plasticity but it also is clear that it can strike both ways.

In this study the reduction in area of the fractured specimen has been used to quantify plasticity. It is now agreed by researchers that this or the euivalent reduction in diameter gives the most relevant information. Actually it has been claimed that defect free working requires a reduction of diameter of at least $40 \% \cdot{ }^{15)}$

\section{Laboratory Steels and Gleeble Testing}

Experience and the statistical study showed that steels rather low in carbon and high in manganese were sensitive to transverse surface cracking, wherefore the influence of different elements was studied by permutating the concentration of the element in question round such a base analysis. The experimental heats were melted in a $50 \mathrm{~kg}$ HF furnace and poured into cast iron moulds. It was deemed that ingots of $50 \mathrm{~kg}$ solidified at about the same rate as slabs, wherefore also the microsegregation pattern would be about the same. From the ingots the specimen blanks were cut longitudinally and rather near to the ingot surface so that the specimen was plastically deformed transverse to the solidification growth direction just as in real rebending. The cycle used for simulation in the present study is shown in Fig. 1. Except for oscillations the cooling cycle conforms in grand features with that of a real strand surface and so does the deformation rate used $1 \sim 2 \times 10^{-4} \mathrm{sec}^{-1}$. The specimen was rapidly heated, soaked at $1300^{\circ} \mathrm{C}$ for $5 \mathrm{~min}$ before cooling down. The deformation temperature was held constant till fracture. Testing was performed in inert gas.

\section{Metallographic Observations}

The specimen is resistance heated and the clamps are water cooled, which means that only some $12 \mathrm{~mm}$ 
of the specimen is redhot. On fracture the current is broken and the heat is drained to the cooler parts of the specimen, similar to a water quench. This means that the structure is frozen in, i.e., austenite transforms to martensite or bainite and the grain boundaries and the structure at time of deformation is thus visualised.

Specimens with reduced plasticity showed very large austenite grain in the vicinity of the fracture surface. Also the fracture followed these austenite grain boundaries. Abundant grain boundary cracks in the vicinity but out of the main fracture path were noted. For specimens deformed at temperatures near to the bottom of the plasticity trough the $\gamma$-grain boundaries were blurred or decorated with precipitated ferrite. In specimens deformed at temperatures still lower than the plasticity trough it appeared that most of the austenite was transformed to ferrite and pearlite.

Specimens deformed at high temperature with resulting high reduction in area values were fine grained next to the fracture surface and it was not possible to trace the fracture back to the grain boundaries, they were more of normal transcrystalline fractures. Due to the fine $\gamma$-grain size next to the fracture surface these specimens transformed so rapidly to ferrite that the prior grain net was blurred and could not be ressolved.

From these metallographical observations it is difficult to draw definite conclusions as to mechanisms. It can for instance not be directly shown that the largest $\gamma$-grain sizes gave the lowest plasticity. Typical $\gamma$-grain sizes are 450 to $650 \mu \mathrm{m}$.

Further to this when studying a number of fracture surfaces with SEM it was possible to see that in some

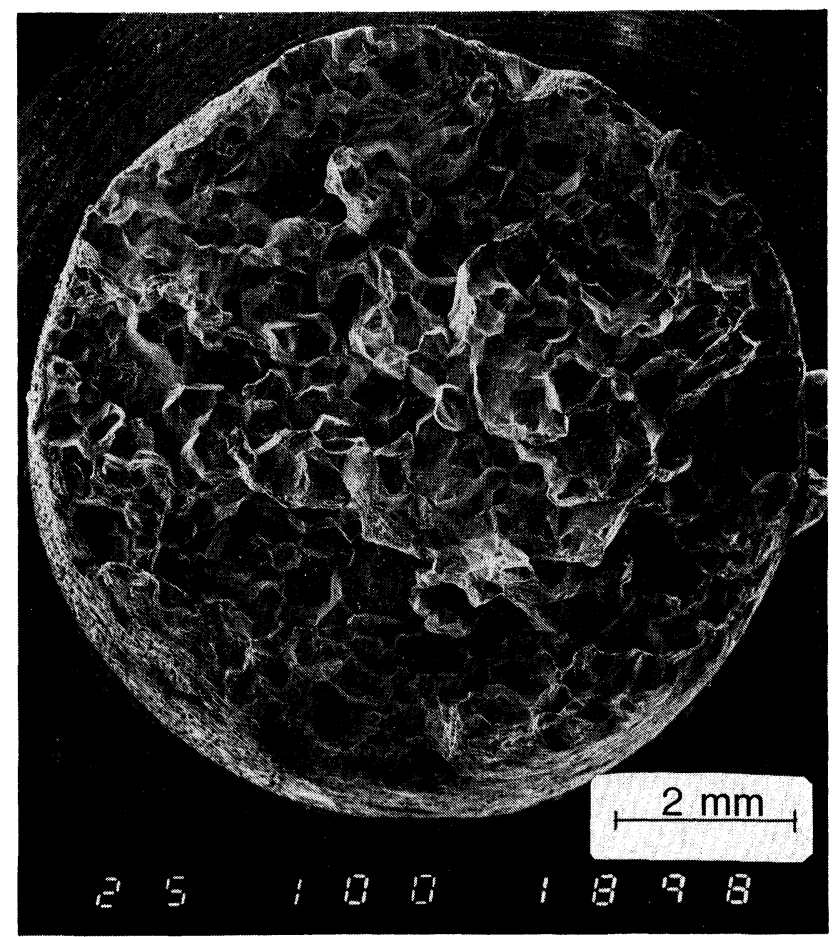

Photo. 1. Gleeble specimen of NbAlN steel deformed to fracture at $800^{\circ} \mathrm{C}$. Note grain boundary fracture facets SEM. cases the ligaments were melted. Thus the experimental technique here suffers a minor drawback. When a very small portion of the area remains there may be a very high specific ampereage over these ligaments leading to melting.

However, on sound specimens it was possible to see both dimple grain boundary fracture and grain facet fractures without dimples indicating that both a wedge cracking mechanism and grain boundary void mechanism could be operating. Also manganese sulphides in the grain boundary fracture surfaces could be observed. Photograph 1 gives a SEM overview.

\section{Results from the Simulation and Discus- sion}

The diagrams in Figs. 2 to 12 reveal an influence which will be discussed for each element together with observations from the literature and the statistical production study.

\section{Carbon}

Steel group A the low temperature steel which showed very high scarfing losses, among other things is characterised by a low carbon content. The statistical evaluation showed that lowering the carbon content increases transverse cracking. The Gleeble study comprised four steels ranging from 0.06 to $0.28 \%$ carbon. As can be seen in Fig. 2 there is a significant influence of carbon on hot plasticity, in the critical temperature range 750 to $900^{\circ} \mathrm{C}$. One explanation could in this case be that carbon suppresses $A_{3}$ about $80 \mathrm{deg}$ over the interval. In production transverse cracking also the increased precipitation of $\mathrm{NbC}$ on raised carbon content should be taken into consideration. This could cancel out some of the adverse effect of lowered carbon shown in the Gleeble study, which was made with niobium free base analysis steels.

\section{Nitrogen}

The statistical study revealed a very strong influence of nitrogen on transverse cracking, however, all steels in that study were aluminium-treated. Figure 3 shows no hot plasticity difference between a steel containing $0.05 \%$ nitrogen and a steel with the double nitrogen content. For a nitrogen content of $0.013 \%$ there seems to be a slight influence at higher rebend temperature, however, the bottom of the trough is unaffected. It seems thus likely that strong detrimental influence of nitrogen encountered

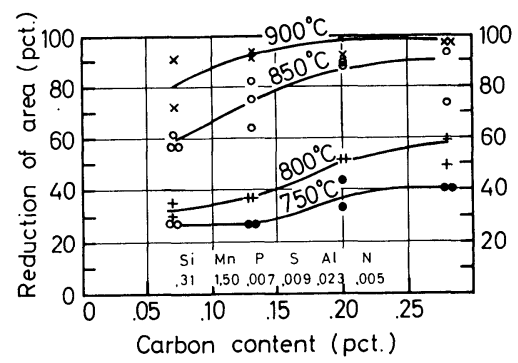

Fig. 2. Influence of carbon on hot plasticity. The average base analyses are given in the figures. 


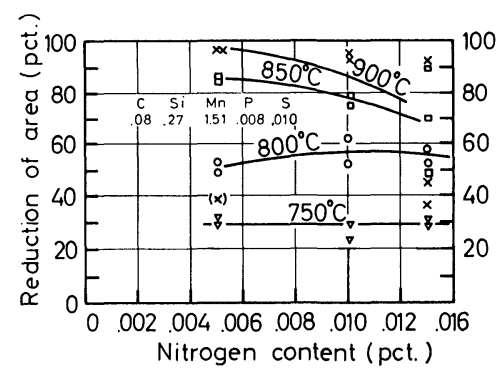

Fig. 3. Influence of nitrogen in an aluminium free steel.

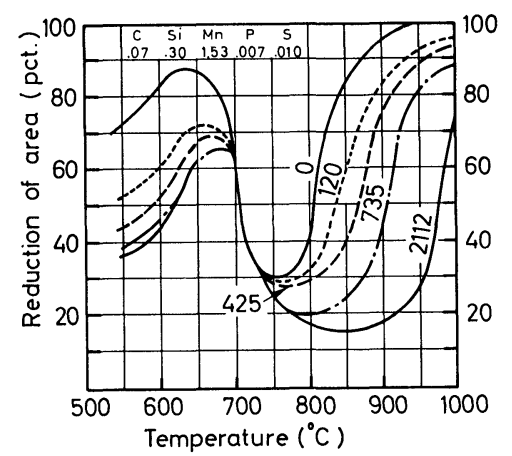

Fig. 4. Influence of $\mathrm{Al} \times \mathrm{N}$ product on hot plasticity.

in practice is the result of a combined influence of nitrogen and aluminium.

\section{Aluminium}

Since rather far back the detrimental influence of aluminium on hot plasticity has been known, ${ }^{16-19)}$ Bernard showed that the low plasticity trough widened with higher product $\mathrm{Al} \times \mathrm{N}$ and this approach has also been tested by us as shown in Fig. 4. It is evident that it is a combined influence of nitrogen and aluminium that is detrimental. A number of physical metallurgical explanations have been offered. A salient view is that the precipitates of AlN in the $\gamma$-grain boundaries cause fracture by affecting grain boundary mobility or by nucleating grain boundary voids. Worth mentioning in this context is the observation by Heritier et al. ${ }^{20)}$ that AIN does not lower plasticity in a steel completely free from sulphur.

\section{Niobium}

The influence of niobium on plasticity has been studied by many workers. Lindblom and Grant ${ }^{21}$ in 1971 demonstrated the detrimental influence of niobium especially at slow deformation rates. The phenomenon thus being known, we only included one heat which contained both aluminium and niobium, and as Fig. 5 shows, niobium further widens the trough to higher temperatures, that is the plasticity really is poor. Similar models as those for aluminium would be natural, and actually Mintz and Arrowsmith ${ }^{7}$ ) have observed fine NbCN precipitates on grain boundary surfaces of Gleeble specimens. Bernard ${ }^{2)}$ suggests that niobium hinders static recrystallization. This results in larger $\gamma$-grains which in turn hampers plasticity. Ouchi and Matsumoto ${ }^{12)}$ found that $\mathrm{Nb}(\mathrm{CN})$ precipitation lowered plasticity

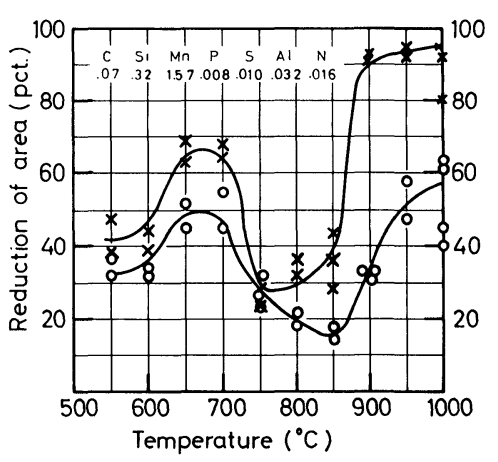

Fig. 5. Influence of niobium on hot plasticity.

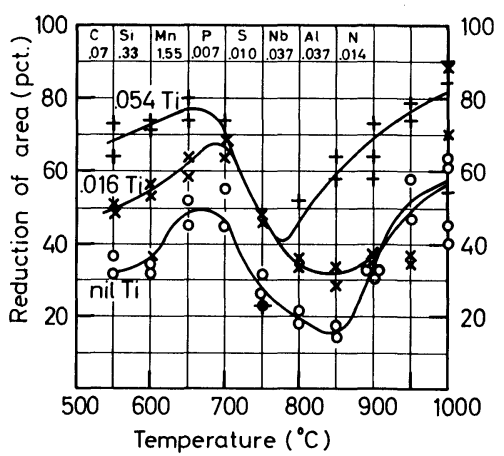

Fig. 6. Influence of Ti on NbAlN steel plasticity.

in the range $800 \sim 900{ }^{\circ} \mathrm{C}$ while at $700 \sim 750{ }^{\circ} \mathrm{C}$ the thickness of the ferrite layers in $\gamma$-grain boundaries primarily controlled plasticity.

\section{Titanium}

Opel and Wagner ${ }^{18)}$ in 1964 showed that hot plasticity in an AIN steel can be completely regained if sufficient titanium is added. This made us conclude that titanium can also be used to suppress transverse cracking in continuous casting. The outcome of the Gleeble study is shown by Fig. 6 . It is evident that a good deal of the plasticity is regained. Probably plasticity drop which may be due to the aluminium and nitrogen content is regained while that of niobium still remains.

It is well known that if titanium is added in excess of nitrogen TiC may form. This phase precipitates in about the same temperature region as $\mathrm{NbC}$. One can thus suspect that higher titanium contents may have an adverse effect like niobium. Credit for such a suspicion is given by earlier plasticity studies with higher amounts of titanium. ${ }^{23)}$ Mintz and Arrowsmith $^{7)}$ tested two heats with titanium and their results may very well be interpreted terms of such a dual influence of titanium on hot plasticity. That the statistical evaluation on one year's production did not show any significant influence of titanium would be due to the sampling as discussed earlier. Here it should only be added that recently also Funnel ${ }^{9}$ ) and Ouchi and Matsumoto ${ }^{12)}$ showed that hot plasticity is regained on the addition of titanium. It should thus be no doubt that when added in stokiometric amounts to an aluminium treated steel the plasticity will be regained. 


\section{Vanadium}

There are examples to be found in the literature of the early sixties ${ }^{17,22}$ that vanadium may cause hot breakage at forging and also own unpublished studies in the late sixties ${ }^{23}$ indicate that higher vanadium contents may hamper hot plasticity. Figure 7 shows the outcome of the present Gleeble study. There is a drop in plasticity in some way proportional to the vanadium content. If, however, vanadium is limited to $0.07 \%$ this drop is rather small. Also Mintz and arrowsmith, ${ }^{7)}$ when studying a $0.07 \%$ vanadium steel, found a small drop in plasticity. That an influence of vanadium did not appear in the statistical study of one year's production may also be explained by the sampling. Further studies of production statistics is recommended.

\section{Boron}

The production statistics for the QT-type steels clearly points to the beneficial influence of boron. This was sustained by Gleeble hot plasticity of four heats with only the boron content varying. It is evident from Fig. 8 the plasticity is improved by minute boron additions and we may ask us why. Part explanation may be offered by the same mechanism as that earlier discussed for titanium. Boron is also an effective nitrogen getter and actually the titanium content is not enough to tie but half of the present nitrogen. The rest could be tied up in boron nitrides. However, it is doubtful whether this explanation is enough. Actually the absolutely best plasticity figures ever obtained at 850 and $800{ }^{\circ} \mathrm{C}$ in this study was for the steels containing 0.005 and $0.010 \%$ boron and probably we have a similar mechanism as that reported for creep resistant austenitic stainless steels and nickel base alloys. A number of explanations have been offered over the years like boron atoms pinning vacancies thereby showing down grain boundary self diffusion. Lagerquist and Lagneborg, ${ }^{24)}$ however, have shown that above a stress of $12 \mathrm{~kg} / \mathrm{mm}^{2}$ grain boundary sliding of boron bearing materials is lower and that this would result in a better creep ductility. Also here it should not be forgotten that boron retards ferrite precipitation in the austenite grain boundaries.

\section{Phosphorous}

Our statistical study (as was then thought surprising) indicated a beneficial influence of raised phosphorous content. A special Gleeble study was therefore decided at, the more as Grant et al. ${ }^{25)}$ in 1960 showed no influence of phosphorous on plasticity in the temperature range 870 to $1200^{\circ} \mathrm{C}$. Meanwhile also Mintz and Arrowsmith ${ }^{7,8)}$ have published Gleeble test data indicating that phosphorous increases hot plasticity. These findings are further sustained by our own Gleeble results for AlNbN base steel in Fig. 9 which show that actually very high phosphorous content lifts up the bottom of the trough. Also for the mild steel base analysis there is a gradual improvement of plasticity at 900 and $1000{ }^{\circ} \mathrm{C}$. Further to this Kirby and Beevers ${ }^{26)}$ showed that plasticity was remarkably

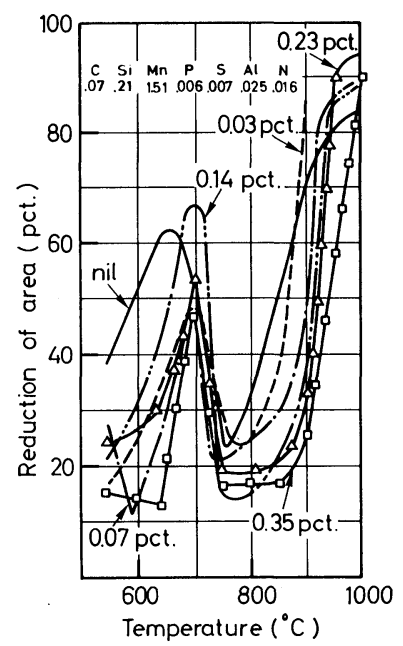

Fig. 7. Influence of vanadium on hot plasticity.

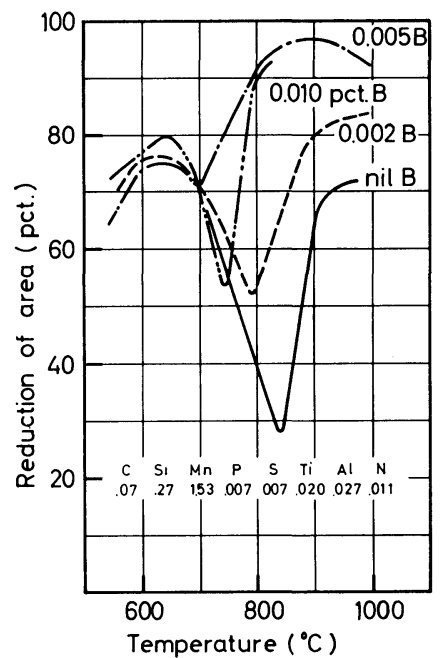

Fig. 8. Influence of boron on plasticity.

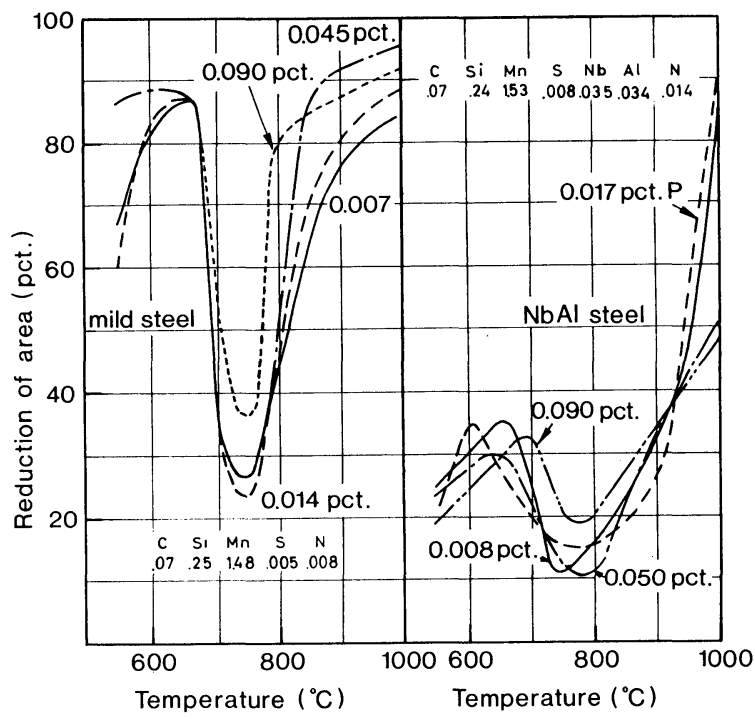

Fig. 9. Influence of phosphorous on hot plasticity.

improved by $0.14 \% \mathrm{P}$ in iron at 400 to $800{ }^{\circ} \mathrm{C}$. They found this to be coupled to a less frequent grain boundary void nucleation which was interpreted in terms of a lowered grain boundary energy. 


\section{Sulphur}

Although the statistical evaluation of one year's production revealed strong indications that sulphur increases transverse cracking and scarfing losses, the Gleeble study that covered a wide span of sulphur contents showed no corresponding influence on hot plasticity. However, it should be born in mind that the manganese content in all Gleeble specimens was around $1.5 \%$. Thus the $\mathrm{Mn} / \mathrm{S}$ ratio varied from 510 down to 15 , which are rather high values at least seen from the solidification and liquation cracking point of view. Further all production steels were aluminium treated thus they have a lower oxygen content which would result in preferential interdendritic precipitation of $\mathrm{MnS}$ which may aggrevate any tendencies to hot shortness. These explanations are actually sustained by a study by Grant et al. ${ }^{27)}$ who showed that first at a $\mathrm{Mn} / \mathrm{S}$ ratio below one the plasticity dropped off and also a low oxygen content resulted in lowered plasticity. The authors point out that the general trend that plasticity drops off when strain rate is lowered does not go with the high sulphur steels. Suzuki et al. ${ }^{3)}$ noted that a low oxygen steel actually showed the reversed strain rate behaviour. They concluded that there are two types of embrittlement, one dependent on oxides and sulphides in the grain boundaries nucleating voids (with the reversed strain rate dependence) and the other mechanism at a somewhat lower temperature where lower strain rate decreases plasticity. This was attributed to intergranular precipitation, formation of proeutectoid films and grain boundary sliding. A very interesting observation made by Heritier et al. ${ }^{20)}$ should be discussed here. They found that AlN in itself does not hamper plasticity. They used extremely clean steel. In steels containing sulphur on the other hand AlN appeared to lower the plasticity significantly. From this they concluded that there were some kind of combined mechanism operating. The present observations that sulphur does not affect plasticity when aluminium is absent lends further support to a suggested mechanism involving a synergic influence of sulphur and aluminium.

\section{Cerium}

In some cases different production routes to a low sulphur steel may be taken. One can use calcium or cerium to increase the cleanliness of the steel. Very vague statistical indications that cerium may influence transver cracking lead us to make Gleeble tests with one cerium treated heat. The result is shown in Fig. 10. No beneficial influence of cerium can be seen. If it is taken into consideration that the cerium-free heat has a lower aluminium content than the cerium treated heat, it should be deemed that cerium actually reduces plasticity to some extent. The effect, however, is next to marginal and as to possible operating mechanisms no guesses will be ventured on here. As in practice a raised cerium content will generally lead to a lowered sulphur content the overall result may be an improved plasticity.

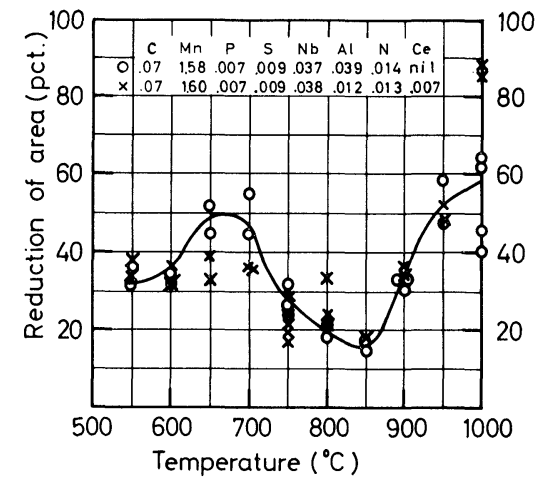

Fig. 10. The influence of cerium on hot plasticity.

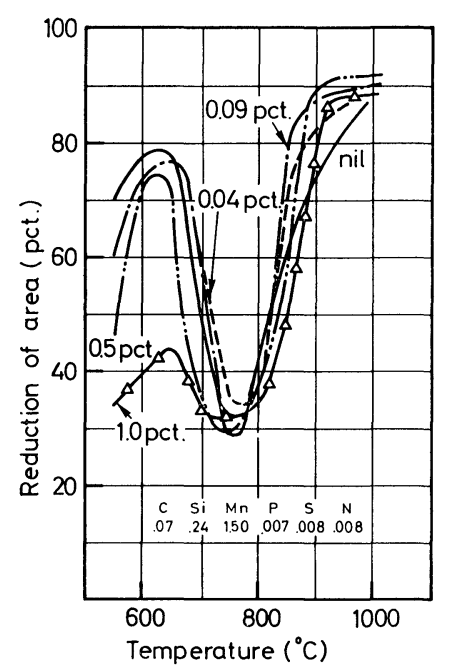

Fig. 11. Influence of copper on mild steel hot plasticity.

\section{Copper}

Research workers consent that metals which readily dissolve in iron have little influence on the hot plasticity. Copper has, however, some reputation in causing red shortness and Bernard has reported of star cracks in continuous casting caused by contamination from the copper mould. However, as shown by Fig. 11, copper in the steel does not hamper plasticity in the high temperature range. In the ferritic range below $700{ }^{\circ} \mathrm{C}$ there seems to be a loss in plasticity at $1 \%$ copper. This might be due to mechanisms similar to those discussed in connection with aluminium and niobium as in the temperature range in question copper would have a tendency to precipitate from the $1 \%$ solid solution.

Here it should be pointed out that Gleeble testing was performed in argon. Actually Burden et al. ${ }^{28)}$ reported on bloom casting that higher copper content increased cracking which may point towards an influence of selective oxidation of the surface of the casting. Further research may thus be needed involving oxidation of the Gleeble specimen. Also statistical studies of surface defect frequencies on scrap based slab production would help to more accurate predictions as to copper.

\section{Molybdenum}

Molybdenum is interesting in the respect of hot plasticity as it is used in steels which are by a major 


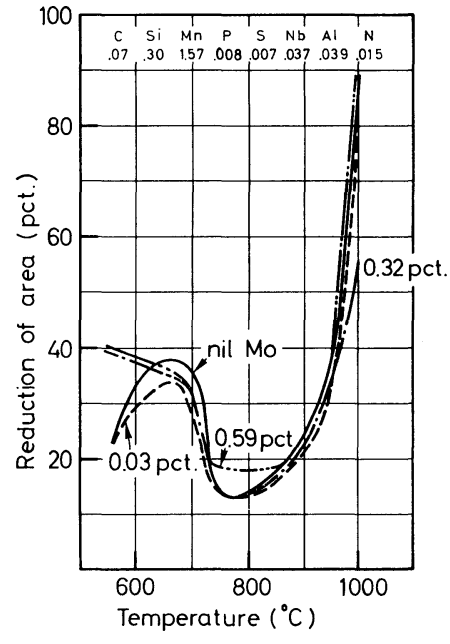

Fig. 12. Influence of molybdenum on plasticity.

steel manufacturer reported not to be too sensitive to transverse cracking namely the X70 type arctic steels. By permutating molybdenum from 0 up to $0.5 \%$ a series of steels ranging from typical low temperature steel to line pipe steel were manufactured. The outcome of this study is shown in Fig. 12. It can be seen that with $0.6 \%$ the bottom of the ductility trough is somewhat lifted, but generally speaking there is no influence at all. It may be that those who cast the molybdenum line pipe steels use a strand with cooling and rebending data well suited for the purpose. As will be discussed in the next section this is probably more important than the chemical composition of the steel.

\section{Conclusions and Practical Consequence}

Primarily it may be concluded that a good, strong, though structural steel, i.e., a low carbon steel treated with both aluminium and niobium or vanadium is inherently susceptible to transverse cracking. The best way therefore would be to use a strand where rebending is set in at a higher temperature where the surface plasticity still is sufficient, i.e., above $1000^{\circ} \mathrm{C}$ or at least above $950^{\circ} \mathrm{C}$. Having stated this, it would be possible already at the projecting and purchasing stage to specify continuous casting machine data that allow for rebending in the high temperature range. As a result of the present project steps in this direction were taken by Svenskt Stäl when in the last years of the seventies new machines were installed and the old outfits modernised. With strand data that make high temperature rebending more or less impossible it is still to some extent feasible by manipulating the watercooling of the surface to avoid rebending in the least plastic range as suggested by different workers. ${ }^{1,12,13,29,30)}$ In this situation, however, it may still remain a necessity to adjust the steel composition in order to minimise cracking, thereby perhaps sacrificing some of the mechanical property benefits of the particular steel composition. Modifications in order to increase transverse cracking resistance could then follow the below list.

(1) Raise carbon content as much as possible.
(2) Avoid aluminium deoxidation.

(3) Keep nitrogen low if aluminium cannot be avoided. In aluminium free steels nitrogen is harmless.

(4) Add some titanium in order to make $\mathrm{AlN}$ precipitation impossible.

(5) Addition of some boron after titanium may have a futher healthy effect on hot plasticity.

(6) Avoid niobium as micro-alloy element, it may be substituted by vanadium.

(7) Purge the steel as to sulphur if possible without the use of aluminium.

Further to the above recommendations the present study moreover has demonstrated:

(8) That rather high phosphorous content in the steel may lessen transverse cracking. This could have practical implications for COR-TEN and Repho type steels.

(9) Molybdenum would have a slight improving effect on plasticity.

Finally it can be concluded that the thermomechanical simulator has proven an excellent tool which may be used to test an alloy as to its susceptibility to transverse cracking.

\section{Acknowledgements}

The author is indebted to many colleagues for advice, help and support. The project was carried through at Oxelösund's Works, Svenskt Stảl AB.

\section{REFERENCES}

1) L. Schmidt and A. Josefsson: Scand. J. Met., 3 (1974), 193

2) G. Bernard: Rev. Mét., 77 (1980), 307.

3) H. G. Suzuki, S. Nishimura and S. Yamaguchi: Trans. ISIJ, 22 (1982). 48.

4) G. Bernard, J. P. Birat, B. Conseil and J. G. Humbert: Rev. Mét., 75 (1978), 467.

5) R. J. Gray, A. Perkins and B. Walker: Int'l. Conf. Solidification and Casting of Metals, Sheffield, 1977, Metals Soc. Book No. 192, (1979), 300.

6) J. R. Wilcox and R.W.K. Honeycombe: Int'l. Conf. Hot Working and Forming Processes, Sheffield, July 1979, Metals Soc. Book No. 264, (1980), 108.

7) B. Mintz and J. M. Arrowsmith: Int'l. Conf. Hot Working and Forming Processes, Sheffield, July 1979, Metals Soc. Book No. 264, (1980), 99.

8) B. Mintz and J. M. Arrowsmith: Metals Technol., 6 (1979), 24.

9) G. D. Funnel: Int'l. Conf. Hot Working and Forming Processes, Sheffield, July 1979, Metals Soc. Book No. 264, (1980), 104.

10) G. D. Funnel and R. J. Davies: Metals Technol., 5 (1978), 150.

11) K. Yamanaka, F. Terasaki, H. Ohtani, M. Oda and M. Yoshihara: Trans. ISIJ, 20 (1980), 810.

12) G. Ouchi and K. Matsumoto: Trans. ISIJ, 22 (1982), 181.

13) T. Nozaki, J. Matsuno, K. Murata, H. Ooi and M. Kodama: Trans. ISIJ, 18 (1978), 330.

14) C. Offerman, G.-Aं. Däcker and C. Enström: Scand. J. Met., 10 (1981), 115.

15) A. Nicholson, D. Smith and P. Shaw: Conf. Deformation under Hot Working Conditions, Sheffield, July 1966, Iron Steel Inst. Publication, (1968), 108. 
16) G. Carlsson: Jernkont. Ann., 148 (1964), 152.

17) W. Dhal and H. Hengstenberg: Arch. Eisenhüttenw., 35 (1964), 1123.

18) P. Opel and S. Wagner: Arch. Eisenhüttenw., 35 (1964), 1113.

19) L. A. Erasmus: JISI, 202 (1964), 32.

20) P. Heritier, A. Fourdeux and A. Kobylanski: Script. Met., 15 (1981), 753.

21) B. E. Lindblom and N. J. Grant: Jernkont. Ann., 155 (1971), 595.

22) L. A. Erasmus: JISI, 202 (1964), 128.

23) N. E. Hannerz and B. E. Lindblom: Letter to the Editor, Jan. 1972, (not published).

24) M. Lagerquist and R. Lagneborg: Scand. J. Met., 1 (1972),
81.

25) R. Nordheim, Th. B. King and N. J. Grant: Trans. Met. Soc. AIME, 218 (1960), 1029.

26) B. R. Kirby and C. J. Beevers: Script. Met., 11 (1977), 659.

27) S. Y. Ogawa, T. B. King and N. J. Grant: Trans. Met. Soc. AIME, 224 (1962), 12.

28) M. H. Burden, G. D. Funnel, A. G. Wittaker and J. M. Young: Int'l. Conf. Solidification and Casting of Metals, Sheffield, 1977, Metals Soc. Book, No. 192, (1979), 279.

29) J. P. Birat, M. Larrecq, A. Le Bon, M. Jeanneau, M. Poupon and D. Senaneuch: Steelmaking Proceedings, Vol. 64, ISS-AIME, Penn., (1981), 53.

30) M. Hashio, M. Kawasaki, T. Watanabe, Y. Ootani and J. Murayama: Trans. ISIJ, 21, (1981), B15. 